\title{
Cardiomyopathy Classification: Ongoing Debate in the Genomics Era
}

\author{
Charles McCartan, ${ }^{1}$ Robert Mason, ${ }^{2}$ S. R. Jayasinghe, ${ }^{2}$ and Lyn R. Griffiths ${ }^{1}$ \\ ${ }^{1}$ Genomics Research Centre, Griffith Health Institute, Griffith University, Parklands Drive, Southport, QLD 4222, Australia \\ ${ }^{2}$ Department of Cardiology, Gold Coast Hospital, Southport Campus, Nerang Street, Southport, QLD 4218, Australia
}

Correspondence should be addressed to Lyn R. Griffiths, l.griffiths@griffith.edu.au

Received 8 March 2012; Revised 14 May 2012; Accepted 31 May 2012

Academic Editor: Aldrin V. Gomes

Copyright ( $\odot 2012$ Charles McCartan et al. This is an open access article distributed under the Creative Commons Attribution License, which permits unrestricted use, distribution, and reproduction in any medium, provided the original work is properly cited.

\begin{abstract}
Cardiomyopathies represent a group of diseases of the myocardium of the heart and include diseases both primarily of the cardiac muscle and systemic diseases leading to adverse effects on the heart muscle size, shape, and function. Traditionally cardiomyopathies were defined according to phenotypical appearance. Now, as our understanding of the pathophysiology of the different entities classified under each of the different phenotypes improves and our knowledge of the molecular and genetic basis for these entities progresses, the traditional classifications seem oversimplistic and do not reflect current understanding of this myriad of diseases and disease processes. Although our knowledge of the exact basis of many of the disease processes of cardiomyopathies is still in its infancy, it is important to have a classification system that has the ability to incorporate the coming tide of molecular and genetic information. This paper discusses how the traditional classification of cardiomyopathies based on morphology has evolved due to rapid advances in our understanding of the genetic and molecular basis for many of these clinical entities.
\end{abstract}

\section{Introduction}

Cardiomyopathies are a broad spectrum of diseases that affect the muscle or myocardium of the heart. This results in a failure of the heart to provide adequate oxygenated blood to the body and remove carbon dioxide and other waste products. The heart is an extremely specialised, richly innervated muscular pump that is designed to beat continuously, without stopping for the entire lifespan of its owner. To put this in perspective, a human heart beating at 70 bpm will beat approximately 2.5 billion times during a 70 year lifespan.

The official definition of cardiomyopathy by the American Heart Association in 2006 is as follows.

"Cardiomyopathies are a heterogeneous group of diseases of the myocardium associated with mechanical and/or electrical dysunction that usually (but not invariably) exhibit inappropriate ventricular hypertrophy or dilatation and are due to a variety of causes that frequently are genetic.
Cardiomyopathies either are confined to the heart or are part of generalized systemic disorders, which may lead to cardiovascular death or progressive heart failure-related disability [1]."

\section{Classification}

There are many ways to classify cardiomyopathies. Previously, a cardiomyopathy was defined as "a heart muscle disease of unknown cause" [3] and was broken down according to their pathophysiological phenotype into dilated cardiomyopathy, hypertrophic cardiomyopathy, or restrictive cardiomyopathy. Since this first classification, major advances have meant that this overly simplistic system needed a more indepth approach to incorporate new clinical entities such as arrhythmogenic right ventricular dysplasia (ARVD) [3, 4].

Therefore in 1995, a task force established by the WHO/ISFC compiled a new system which included ARVD 
TABLE 1: Summary of AHA 2006 classification [1].

\begin{tabular}{ll}
\hline Primary cardiomyopathies & Secondary cardiomyopathies \\
\hline $\begin{array}{l}\text { Genetic (hypertrophic cardiomyopathy; conduction } \\
\text { abnormalities: prolonged QT syndrome; Brugada syndrome) }\end{array}$ & Infiltrative (amyloidosis and Gaucher disease) \\
$\begin{array}{l}\text { Mixed (dilated cardiomyopathy; restrictive cardiomyopathy) } \\
\begin{array}{l}\text { Acquired (inflammatory myocarditis, peripartum, stress } \\
\text { cardiomyopathy_ "broken heart syndrome" or tako-tsubo) }\end{array}\end{array}$ & $\begin{array}{l}\text { Toxicity (drugs, alcohol, heavy metals, and chemicals/chemotherapy) } \\
\text { Inflammatory (sarcoidosis) endocrine (diabetes mellitus; thyroid } \\
\text { disorders; hyperparathyroidism), cardiofacial (Noonan syndrome, } \\
\text { lentiginosis) neuromuscular/neurological, nutritional deficiencies, } \\
\text { and autoimmune and collagen disorders }\end{array}$ \\
\hline
\end{tabular}

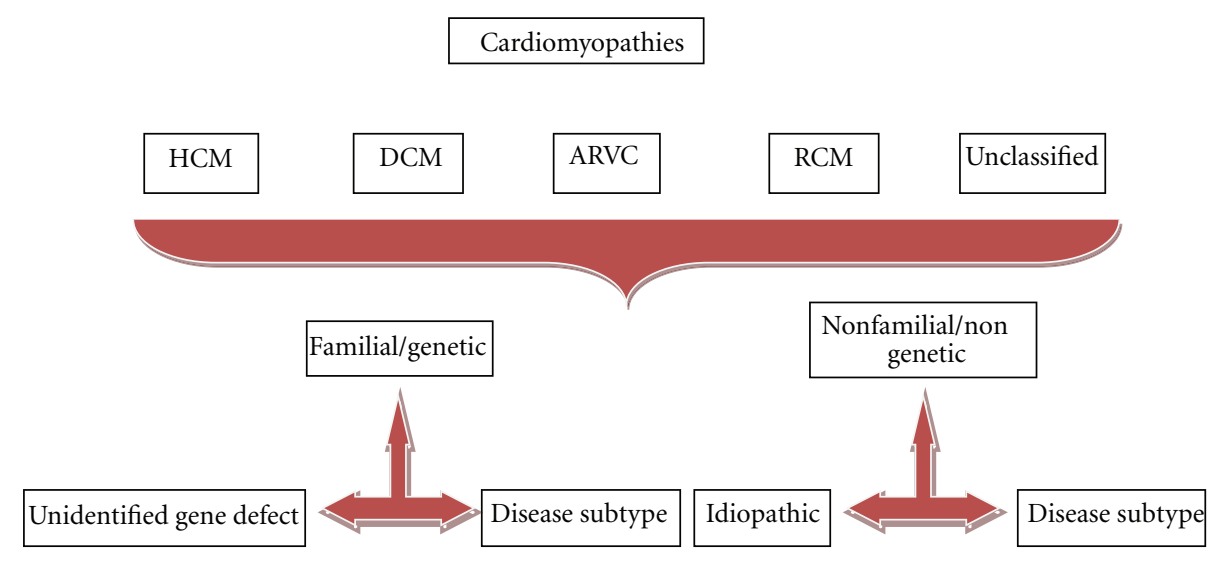

FIGURE 1: Summary of ESC 2008 Classification [2]. DCM: dilated cardiomyopathy; HCM: hypertrophic cardiomyopathy; ARVC: arrhythmogenic right ventricular cardiomyopathy; RCM: restrictive cardiomyopathy.

and unclassified cardiomyopathies (e.g., fibroelastosis, noncompacted myocardium, systolic dysfunction with minimal dilatation, and mitochondrial involvement). The term "specific cardiomyopathy" was used to describe heart muscle disorders which are as a result of cardiac or systemic diseases such as coronary artery disease, valvular heart disease, or hypertension [61].

A more complete classification based on the AHA definition above divides cardiomyopathies into (1) primary cardiomyopathies, which affect the heart alone, and (2) secondary cardiomyopathies, which are the result of a systemic illness affecting many other parts of the body. These are then further broken down into subgroups within these two broad categories incorporating new genetic and molecular insights (Table 1).

Distinguishing between primary and secondary cardiomyopathies can be challenging as many diseases classified as primary can have extra cardiac components, and many secondary cardiomyopathies can mainly or exclusively affect the heart. Whether or not this is the best method of classification has generated some debate within the literature $[62,63]$. With our growing understanding of the genomic and molecular markers made available by modern laboratory research, a new approach had been proposed to address this overlap based on the causative mutation implicated in causing the disease $[64,65]$. The working group from the European Society of Cardiology (ESC) in 2008 defined cardiomyopathy as follows.

\begin{abstract}
"A myocardial disorder in which the heart muscle is structurally and functionally abnormal, in the absence of coronary artery disease, hypertension, valvular disease and congenital heart disease sufficient to cause the observed myocardial abnormality [2].”
\end{abstract}

While diagnosis of cardiomyopathy rarely begins with the identification of a genetic mutation, it is rational to incorporate genetic mutation testing within a framework of classification as it is important while formulating a plan of treatment and also in informing families of their prognosis (Figure 1).

2.1. Hypertrophic Cardiomyopathy (HCM). Hypertrophic cardiomyopathy (HCM) has been defined by the presence of myocardial hypertrophy incongruent with the haemodynamic stress required for the degree of hypertrophy and the exclusion of infiltrative diseases such as amyloidosis and storage diseases $[2,66,67]$.

In the absence of hypertension and valve disease, left ventricular hypertrophy (LVH) occurs in approximately $1: 500$ of the general population [68]. In day-to-day clinical practice it is very difficult to differentiate between pathologies using minimally invasive techniques such as cardiac echo or cardiac magnetic resonance imaging (MRI). Histological demonstration (on myocardial biopsy) of myocyte hypertrophy in the definition of HCM is unreliable due to the patchy 
TABLE 2: Genes associated with hypertrophic cardiomyopathy.

\begin{tabular}{|c|c|c|c|}
\hline Gene & Protein & Function & Reference \\
\hline$\beta-\mathrm{MHC}$ & $\beta$-Myosin heavy chain & Sarcomere protein & {$[5]$} \\
\hline$\alpha-\mathrm{MHC}$ & $\alpha$-Myosin heavy chain & Sarcomere protein & {$[6,7]$} \\
\hline cMYBPC & Cardiac myosin-binding protein $\mathrm{C}$ & Sarcomere protein & {$[8,9]$} \\
\hline cTnI & Cardiac troponin I & Sarcomere protein & {$[10]$} \\
\hline $\mathrm{cTnT}$ & Cardiac troponin $\mathrm{T}$ & Sarcomere protein & {$[11]$} \\
\hline $\mathrm{cTnC}$ & Cardiac troponin $\mathrm{C}$ & Sarcomere protein & {$[12]$} \\
\hline$\alpha$-TM & $\alpha$-Tropomyosin & Sarcomere protein & {$[11]$} \\
\hline MLC-1 & Myosin essential light chain & Sarcomere protein & {$[13]$} \\
\hline MLC-2 & Myosin regulatory light chain & Sarcomere protein & {$[7]$} \\
\hline ACTC & Actin & Sarcomere protein & {$[14]$} \\
\hline TTN & Titin & Sarcomere protein & {$[15,16]$} \\
\hline \multicolumn{4}{|c|}{ Metabolic phenocopies } \\
\hline PRKAG2 & AMP kinase & & {$[17]$} \\
\hline LAMP2 & Lysosome membrane protein & & [18] \\
\hline
\end{tabular}

nature of the abnormality within the myocardium. The position statement from the ESC [2] contained the following "the presence of intramyocardial storage material is not an exclusion criterion for HCM.... Instead, hypertrophic cardiomyopathies are simply defined by the presence of increased ventricular wall thickness or mass in the absence of loading conditions (hypertension, valve disease) sufficient to cause the observed abnormality." The "potential inaccuracy" in not fully excluding infiltrative disease or demonstrating myocyte hypertrophy on biopsy is justified by leading to increased emphasis in the clinical picture and a promise of better minimally invasive diagnostic strategies.

If the HCM is familial, then it is usually transmitted in an autosomal dominant pattern of inheritance caused by mutations within genes that encode for various proteins of the cardiac sarcomere. Currently, there are over 500 mutations in 13 genes that have been identified that cause HCM and 50\% of these are familial [66, 69-72] (Table 2).

Pathologically, left ventricular (LV) cavity size is normally reduced and this can progress to LV dilatation and heart failure, albeit in a minority of patients. There are many patterns of hypertrophy and all are consistent with a diagnosis of HCM but concentric hypertrophy is more suggestive of a systemic cause such as glycogen storage disease. Moreover, mutations in the genes encoding for cardiac troponins can be associated with mild phenotypes but, conversely, a high incidence of cardiac death [73]. The normal physiological hypertrophy that occurs in highly competitive athletes is uncommon (less than $2 \%$ of male athletes) [74], but it is important not to miss HCM in these individuals as the risk of sudden death is unacceptably high [75] and causes great distress to both families and communities who have been affected.

2.2. Restrictive Cardiomyopathy. Restrictive cardiomyopathies have a diverse range of aetiology; however, all are recognised as having distinct haemodynamic features separating them from other forms of cardiomyopathy. Restrictive cardiomyopathies in general are defined as showing normal ventricular size (nondilated and nonhypertrophied) with impaired haemodynamic function, elevated filling pressures, and diastolic dysfunction, and in most cases normal systolic function $[76,77]$.

Presentation can include symptoms of both right and left sided failure; decreased exercise tolerance, dyspnoea, peripheral oedema, and palpitations are the most common symptoms [77]. Due to the contrast in both aetiology and treatment options and the similarities in haemodynamics, it is important to recognise the difference between restrictive cardiomyopathy and constrictive pericarditis. Usually, this is defined with a variety of investigatory modalities with both haemodynamic and morphological assessment and includes echocardiography and pericardial imaging [78].

Various aetiologies have been identified as causing restrictive cardiomyopathy and range from idiopathic (primary) restrictive cardiomyopathy, to systemic conditions including infiltrative, noninfiltrative, and storage disorders, as well as endomyocardial disorders, various medications, and iatrogenic causes [79]. Familial restrictive cardiomyopathies are usually inherited in an autosomal dominant fashion, the genetic basis of which remains to be identified, and are noted to be relatively rare [80]. Hereditary conditions known to cause a restrictive cardiomyopathy include haemochromatosis, glycogen storage diseases, Fabry's disease, Gaucher's disease, and Hurler syndrome.

Prognosis in symptomatic patients is quite poor, depending on aetiology. Idiopathic restrictive cardiomyopathy has been associated with a significant difference in 10-yr survival when compared to expected survival in groups matched for age and sex [81]. In comparison with other forms of cardiomyopathy, restrictive cardiomyopathy is relatively uncommon, though it still demonstrates an appreciable incidence in some population groups, namely, Asia, South and Central America [79].

2.3. Dilated Cardiomyopathy (DCM). DCM is a common cause of congestive cardiac failure (CCF) and is defined by the presence left ventricular systolic dysfunction with left 
TABLE 3: Genes associated with dilated cardiomyopathy.

\begin{tabular}{|c|c|c|c|}
\hline Gene & Protein & Function & Reference \\
\hline \multicolumn{4}{|c|}{ Autosomal dominant } \\
\hline ACTC & Cardiac actin & Sarcomere protein & {$[19]$} \\
\hline DES & Desmin & Dystrophin-associated glycoprotein complex & {$[20]$} \\
\hline SGCD & $\delta$-Sarcoglycan & Dystrophin-associated glycoprotein complex & {$[21]$} \\
\hline MYH7 & $\beta$-Myosin heavy chain & Sarcomere protein & {$[22,23]$} \\
\hline TNNT2 & Cardiac troponin $\mathrm{T}$ & Sarcomere protein & {$[22,24,25]$} \\
\hline TPM1 & $\alpha$-Tropomyosin & Sarcomere protein & {$[26]$} \\
\hline TTN & Titin & Sarcomere structure & {$[27]$} \\
\hline VCL & Metavinculin & Intercalated discs & {$[28]$} \\
\hline MYBPC & Myosin-binding protein $\mathrm{C}$ & Sarcomere protein & {$[23]$} \\
\hline MLP/CSRP3 & Muscle LIM protein & $\mathrm{Z}$ discs & [29] \\
\hline ACTN2 & $\alpha$-Actinin-2 & Sarcomere structure & {$[30]$} \\
\hline MYH6 & $\alpha$-Myosin heavy chain & Sarcomere protein & {$[31]$} \\
\hline $\mathrm{ABCC}$ & SUR2A & Cardiac K channel & {$[32]$} \\
\hline LMNA & Lamin A/C & Nuclear membrane protein & {$[33]$} \\
\hline PLN & Phospholamban & Sarcoplasmic reticulum Ca regulator & {$[34,35]$} \\
\hline ZASP/LBD3 & Cypher & Cytoskeletal assembly & {$[36]$} \\
\hline \multicolumn{4}{|c|}{ X linked } \\
\hline DMD & Dystrophin & \multirow{2}{*}{ Dystrophin-associated glycoprotein complex } & {$[37,38]$} \\
\hline TAZ/G4.5 & Tafazzin & & {$[39,40]$} \\
\hline \multicolumn{4}{|c|}{ Recessive } \\
\hline TNNI3 & Troponin I & Sarcomere protein & {$[41]$} \\
\hline
\end{tabular}

ventricular dilatation the absence of coronary artery disease or other causes such as hypertension or valvular pathology [2]. The right ventricle may be involved but is not necessary for the diagnosis. The exact prevalence of DCM in the general population is unknown, but it clearly varies with age and geography and is the most common diagnosis in patients referred for cardiac transplantation $[82,83]$. Around 30$50 \%$ of cases have a familial component $[71,84]$, and more than 30 genes have been identified, to date, that cause DCM (Table 3). Most are inherited in an autosomal dominant fashion although some can be autosomal recessive, X-linked or mitochondrial. The actual frequency of familial DCM is probably underestimated.

The 2009 HFSA [71] has released guidelines on the diagnosis and treatment of patients with DCM. A careful family history of three or more generations of family members should be elicited including unexplained heart failure and sudden death in family members before the age of 60 without any symptoms of coronary artery disease. The diagnosis of familial DCM can be made when there are three or more close family members with unexplained DCM. Screening of family members can then take place; this should happen with or without genetic testing and is supported by the fact that many patients can be asymptomatic despite being affected. The 2009 HFSA made the following recommendations for screening: full history, focusing on symptoms of heart failure (dyspnoea, syncope, presyncope, and palpitations); physical examination; ECG; Echo; CK MM. First-degree relatives who have negative findings on initial screening should be rescreened in three- to five-year intervals, but if there are any abnormal findings during the initial screen, the patient should be rescreened in one year.

Peripartum cardiomyopathy is a specific subgroup of dilated cardiomyopathy defined as the development of heart failure with evidence of left ventricular dysfunction, within the last month of pregnancy to within 5 months of delivery, without other identifiable cause or underlying cardiac condition $[85,86]$. Groups of women presenting during the earlier stages of pregnancy have been identified and with similar epidemiological characteristics and with similar disease progression and outcomes. The earlier time frame of presentation has been postulated to represent part of a spectrum of peripartum cardiomyopathy [87]. In the group of women presenting in the early stages of pregnancy, search for underlying cardiac conditions (valvular, ischaemic, and myocardial) should be approached. Peripartum cardiomyopathy affects approximately 1:4000 women across the US and Europe each year, with higher rates noted across the African continent [88]. The condition usually presents with dyspnoea, cough, peripheral oedema, orthopnoea, paroxysmal nocturnal dyspnoea, generalised fatigue, and chest discomfort. Investigations including new ECG finding of arrhythmia, chest X-ray with foetal shielding (if required for diagnosis of pulmonary oedema) showing cardiomegaly, pulmonary venous congestion and interstitial oedema, and an elevated BNP or NT-proBNP level further suggest the presence of peripartum cardiomyopathy [89]. Echocardiographic evidence demonstrating LV enlargement, a LV end-systolic dimension greater than $2.7 \mathrm{~cm} / \mathrm{m}^{2}$ of body surface area, LVEF less than $45 \%$ and/or fractional 
TABLE 4: Genes associated with ARVD.

\begin{tabular}{|c|c|c|c|c|}
\hline Locus & Gene & Protein & Function & References \\
\hline ARVD1 & TGFB3 & Transforming growth factor $\beta 3$ & Cell signalling & {$[42,43]$} \\
\hline ARVD2 & RYR2 & Ryanodine receptor 2 & Sarcoplasmic reticulum calcium channel & {$[44,45]$} \\
\hline ARVD3 & Not known & [46] & & \\
\hline ARVD4 & Not known & [47] & & \\
\hline ARVD5 & LAMR1 & Extracellular matrix glycoprotein & Cell signalling, adhesion, and migration & {$[48,49]$} \\
\hline ARVD6 & PTPLA & Protein-tyrosine phosphatase-like member A & Fatty acid synthesis & {$[50,51]$} \\
\hline ARVD7 & DES; ZASP & Desmosomal protein; PDZ domain protein & $\begin{array}{l}\text { Dystrophin-associated glycoprotein complex, and } \\
\text { Cytoskeletal assembly }\end{array}$ & {$[52,53]$} \\
\hline ARVD8 & DSP & Desmoplakin & Anchoring of intermediate filaments & {$[53,54]$} \\
\hline ARVD9 & PKP2 & Plakophilin 2 & Cell adhesion & {$[55,56]$} \\
\hline ARVD10 & DSG2 & Desmoglein 2 & Calcium-binding transmembrane glycoprotein & {$[57,58]$} \\
\hline ARVD11 & DSC2 & Desmocollin 2 & Calcium-dependent glycoprotein & {$[59,60]$} \\
\hline
\end{tabular}

shortening less than 30 percent, conclude the presence of heart failure. The use of cardiac MRI in the diagnosis and evaluation of peripartum cardiomyopathy is currently being explored and the presence or lack thereof of late gadolinium enhancement as a prognostic feature in peripartum cardiomyopathy $[90,91]$. The aetiology of peripartum cardiomyopathy has been unclear for many years; however, new research into an inflammatory or immunological basis, and the role of prolactin in the development of the disease has shed new light on the causative mechanisms that may be behind this condition. Familial clustering of peripartum cardiomyopathy has been identified; however, on screening other family members and with further genetic testing, this clustering may represent a subset of undiagnosed familial dilated cardiomyopathy. TNF alpha, and other proinflammatory cytokines have been shown to be elevated in a large number of peripartum cardiomyopathy cases and similarly some studies have suggested a role for autoantibodies against normal human cardiac tissues proteins and further research is required in this area [92]. Higher levels of CRP, Fas/Apo1 , TNF alpha and IL- 6 have been demonstrated in some population groups with peripartum cardiomyopathy and have implicated a role for inflammatory mediator in the disease process $[93,94]$. The use of immunoglobulin and antitumour necrosis factor agents as therapy for peripartum cardiomyopathy has been trialled based on these observations in several smaller pilot studies [95, 96]. Evidence implicating myocarditis as a causative factor is varied however may suggest the presence of myocarditis in 7.8-8.8\% of cases [97]. The role of an altered form of prolactin in the pathophysiology of peripartum cardiomyopathy has been explored of late in animal models. Mice with cardiac tissuespecific STAT3 knockout have shown an increased cleavage of prolactin (a pituitary hormone released cyclically in varying degrees in the pregnant state) mediated by cathespsin $\mathrm{D}$ to its proapoptotic and antiangiogenic form, $16 \mathrm{kDa}$ prolactin and have subsequently demonstrated the development of peripartum cardiomyopathy [98]. In light of this research, further preliminary studies have taken place on the use of bromocriptine as a therapy for women developing peripartum cardiomyopathy this small trials conducted thus far have shown a mortality benefit [99]. Peripartum cardiomyopathy, although rare, is an important entity affecting the pregnant woman, with significant morbidity and mortality consequences. Recent research into the pathophysiology behind the disease may allow for further subclassification of this disease, and hence earlier diagnosis, and new novel therapies in its treatment.

2.4. Arrhythmogenic Right Ventricular Dysplasia (ARVD). ARVD is a heart muscle disease which, pathologically, consists of progressive fibrofatty replacement of the right ventricular musculature which may or may not involve the left ventricle. It predisposes towards malignant arrhythmias originating from the right ventricle and is a major cause of sudden death in young athletes [100]. Major and minor criteria of ARVD diagnosis have been compiled, and the diagnosis can be made if there are two major, one major and one minor or four minor criteria present [101]. Diagnosis and risk stratification are extremely important as there are proven life saving interventions which are available to the clinician [102].

It is a familial disease in around $50 \%$ of cases and is usually transmitted in an autosomal dominant fashion [103]. The first gene, ARVD1, coding for a desmosome protein, was discovered in 1994 [42], and since then multiple causative genes relating to the desmosome have been discovered, indicating that ARVD is a disease of the desmosome $[55,57$, 104-107] (Table 4).

Genetics is obviously important as it adds certainty to the diagnosis, but given the incomplete penetrance of the disease the established diagnostic criteria are essential.

\section{Discussion}

The 2009 Heart Failure Society of America (HFSA) genetic evaluation of cardiomyopathy practice guideline and 2005 American College of Cardiology/American Heart Association (ACC/AHA) HF guidelines include recommendations with regard to genetic counselling and genetic testing in patients and families with certain cardiomyopathies. As far 
as treatments are concerned, gene therapy is still quite young and transferring concepts from animal models to human therapies is yet to be seen. Therapeutic interventions of the future are likely to focus on the signaling events from abnormal gene to protein and finally clinical phenotype, and the modification of the genetic and environmental factors mediating this process [108].

As sudden cardiac death is a possible first presenting complaints for patients with dilated cardiomyopathy especially those with LMNA gene defects (where penetrance rates are noted to be very high over 30 years and associated with high rates of sudden death) and in particular SCN5A defects, early implantation of ICD may be considered in these populations, especially in the setting of family history of sudden cardiac death or implantable cardiac defibrillator usage [109].

Gene therapy in animal models of heart failure aimed at improving sarcoplasmic calcium transport has been investigated with therapeutic promise and may lead to further application in human model of restrictive cardiomyopathy [110].

In patients with ARVC, genotyping and early ICD implantation as primary prevention may be indicated in patients with Naxos disease and recessive forms of ARVC [111].

3.1. The Impact of Genetic and Genomic Approaches on Current and Future Clinical Application. Screening of family members of patients with dilated cardiomyopathy, hypertrophic cardiomyopathy, and arrhythmogenic right ventricular is recommended as family members are frequently asymptomatic and disease progression is often quite short and although asymptomatic early noninvasive investigations may prove abnormal [112, 113].

Due to the commonality of autosomal dominant inheritance of hypertrophic cardiomyopathy and the high degree of penetrance associated with many of the gene mutations, it is recommended that first-degree relatives are regularly screened for inheritance of the disease [114]. With the likely increase in amount of genetic testing the impact on family members of patients with an inheritable disease is likely to be affected significantly, particularly with many defects identified showing varying degrees of expression and penetrance. The role of genetic counselling will become more and more important as further genetic variants are identified with unknown pathological and prognostic significance.

For example, patients with gene mutations of desmosomal components (those most commonly seen in ARVC), penetrance is low and there is commonly age related variability in expression and therefore, early identification holds an unknown prognostic significance for patients in question $[115,116]$.

\section{Conclusion}

Classification systems in all branches of science are designed to allow categorisation within a consistent framework thereby imparting a degree of homogeneity to satisfy researchers and clinicians alike. Over the years, many classification systems have been put forward for cardiomyopathy based on origin, structural abnormality, functional status, and etiology. Not surprisingly, this has failed to some degree. From a purely functional viewpoint, cardiomyopathy is not a static condition but can move from one functional group to another due to cardiac remodelling. Similarly, using etiology has limitations given that similar genotypes can express different phenotypes depending on where the disease is in its natural history. Despite these shortcomings, a genetic diagnosis does offer some definite advantages. Karibe et al. reported a novel tropomyosin mutation that was associated with a mild phenotype but had a poor prognosis when contrasted to other mutations in the gene (13 deaths in 26 affected family members) [117]. Genetic testing in such cases allows identification of patients which would benefit from primary ICD implantation as well as a definitive diagnosis in conjunction with traditional methods. Similarly, patients with mutations in the gene for cardiac myosin-binding protein $\mathrm{C}$ can have a favourable clinical course due to the fact that the cardiomyopathy may not be expressed until later in life. Therefore, prolonged lifetime screening for family members who do not have the mutation can be avoided by genetic testing within these individuals [118]. There has been some debate on the value of genetic testing, with the debate focusing on the ability of genetic testing to accurately predict clinical course [119]; however, genetic testing allows clinicians to move beyond unexplained ventricular abnormalities and definitively identify not only who has the disease but what the cause is and what are the likely outcomes. Changing the natural history of a disease starts with accurate diagnosis.

\section{References}

[1] B. J. Maron, J. A. Towbin, G. Thiene et al., "Contemporary definitions and classification of the cardiomyopathies. An American Heart Association Scientific Statement from the Council on Clinical Cardiology, Heart Failure and Transplantation Committee; Quality of Care and Outcomes Research and Functional Genomics and Translational Biology Interdisciplinary Working Groups; and Council on Epidemiology and Prevention," Circulation, vol. 113, no. 14, pp. 1807-1816, 2006.

[2] P. Elliott, B. Andersson, E. Arbustini et al., "Classification of the cardiomyopathies: a position statement from the european society of cardiology working group on myocardial and pericardial diseases," European Heart Journal, vol. 29, no. 2, pp. 270-276, 2008.

[3] F. I. Marcus, G. H. Fontaine, and G. Guiraudon, "Right ventricular dysplasia: a report of 24 adult cases," Circulation, vol. 65, no. 2, pp. 384-398, 1982.

[4] G. Thiene, A. Nava, D. Corrado, L. Rossi, and N. Pennelli, "Right ventricular cardiomyopathy and sudden death in young people," New England Journal of Medicine, vol. 318, no. 3, pp. 129-133, 1988.

[5] A. A. T. Geisterfer-Lowrance, S. Kass, G. Tanigawa et al., "A molecular basis for familial hypertrophic cardiomyopathy: a $\beta$ cardiac myosin heavy chain gene missense mutation," Cell, vol. 62 , no. 5, pp. 999-1006, 1990. 
[6] G. Tanigawa, J. A. Jarcho, S. Kass et al., "A molecular basis for familial hypertrophic cardiomyopathy: an $\alpha / \beta$ cardiac myosin heavy chain hybrid gene," Cell, vol. 62, no. 5, pp. 991998, 1990.

[7] H. Niimura, K. K. Patton, W. J. McKenna et al., "Sarcomere protein gene mutations in hypertrophic cardiomyopathy of the elderly," Circulation, vol. 105, no. 4, pp. 446-451, 2002.

[8] H. Watkins, D. Conner, L. Thierfelder et al., "Mutations in the cardiac myosin binding protein-C gene on chromosome 11 cause familial hypertrophic cardiomyopathy," Nature Genetics, vol. 11, no. 4, pp. 434-437, 1995.

[9] G. Bonne, L. Carrier, J. Bercovici et al., "Cardiac myosin binding protein- $\mathrm{C}$ gene splice acceptor site mutation is associated with familial hypertrophic cardiomyopathy," Nature Genetics, vol. 11, no. 4, pp. 438-440, 1995.

[10] A. Kimura, H. Harada, J.-E. Park et al., "Mutations in the cardiac troponin I gene associated with hypertrophic cardiomyopathy," Nature Genetics, vol. 16, no. 4, pp. 379-382, 1997.

[11] L. Thierfelder, H. Watkins, C. MacRae et al., " $\alpha$-tropomyosin and cardiac troponin $\mathrm{T}$ mutations cause familial hypertrophic cardiomyopathy: a disease of the sarcomere," Cell, vol. 77, no. 5, pp. 701-712, 1994.

[12] B. Hoffmann, H. Schmidt-Traub, A. Perrot, K. J. Osterziel, and R. Gessner, "First mutation in cardiac troponin C, L29Q, in a patient with hypertrophic cardiomyopathy," Human mutation, vol. 17, no. 6, p. 524, 2001.

[13] K. Poetter, H. Jiang, S. Hassanzadeh et al., "Mutations in either the essential or regulatory light chains of myosin are associated with a rare myopathy in human heart and skeletal muscle," Nature Genetics, vol. 13, no. 1, pp. 63-69, 1996.

[14] T. M. Olson, T. P. Doan, N. Y. Kishimoto, F. G. Whitby, M. J. Ackerman, and L. Fananapazir, "Inherited and de novo mutations in the cardiac actin gene cause hypertrophic cardiomyopathy," Journal of Molecular and Cellular Cardiology, vol. 32, no. 9, pp. 1687-1694, 2000.

[15] B. L. Siu, H. Niimura, J. A. Osborne et al., "Familial dilated cardiomyopathy locus maps to chromosome 2q31," Circulation, vol. 99, no. 8, pp. 1022-1026, 1999.

[16] M. Satoh, M. Takahashi, T. Sakamoto, M. Hiroe, F. Marumo, and A. Kimura, "Structural analysis of the titin gene in hypertrophic cardiomyopathy: identification of a novel disease gene," Biochemical and Biophysical Research Communications, vol. 262, no. 2, pp. 411-417, 1999.

[17] M. H. Gollob, M. S. Green, A. S. L. Tang, and R. Roberts, "PRKAG2 cardiac syndrome: familial ventricular preexcitation, conduction system disease, and cardiac hypertrophy," Current Opinion in Cardiology, vol. 17, no. 3, pp. 229-234, 2002.

[18] M. Arad, B. J. Maron, J. M. Gorham et al., "Glycogen storage diseases presenting as hypertrophic cardiomyopathy," New England Journal of Medicine, vol. 352, no. 4, pp. 362-372, 2005.

[19] T. M. Olson, V. V. Michels, S. N. Thibodeau, Y. S. Tai, and M. T. Keating, "Actin mutations in dilated cardiomyopathy, a heritable form of heart failure," Science, vol. 280, no. 5364, pp. 750-752, 1998.

[20] D. Li, T. Tapscoft, O. Gonzalez et al., "Desmin mutation responsible for idiopathic dilated cardiomyopathy," Circulation, vol. 100, no. 5, pp. 461-464, 1999.

[21] S. Tsubata, K. R. Bowles, M. Vatta et al., "Mutations in the human $\delta$-sarcoglycan gene in familial and sporadic dilated cardiomyopathy," Journal of Clinical Investigation, vol. 106, no. 5, pp. 655-662, 2000.
[22] M. Kamisago, S. D. Sharma, S. R. DePalma et al., "Mutations in sarcomere protein genes as a cause of dilated cardiomyopathy," New England Journal of Medicine, vol. 343, no. 23, pp. 1688-1696, 2000.

[23] S. Daehmlow, J. Erdmann, T. Knueppel et al., "Novel mutations in sarcomeric protein genes in dilated cardiomyopathy," Biochemical and Biophysical Research Communications, vol. 298, no. 1, pp. 116-120, 2002.

[24] D. Li, G. Z. Czernuszewicz, O. Gonzalez et al., "Novel cardiac troponin $\mathrm{T}$ mutation as a cause of familial dilated cardiomyopathy," Circulation, vol. 104, no. 18, pp. 2188-2193, 2001.

[25] E. L. Hanson, P. M. Jakobs, H. Keegan et al., "Cardiac troponin $\mathrm{T}$ lysine 210 deletion in a family with dilated cardiomyopathy," Journal of Cardiac Failure, vol. 8, no. 1, pp. 28-32, 2002.

[26] T. M. Olson, N. Y. Kishimoto, F. G. Whitby, and V. V. Michels, "Mutations that alter the surface charge of alphatropomyosin are associated with dilated cardiomyopathy," Journal of Molecular and Cellular Cardiology, vol. 33, no. 4, pp. 723-732, 2001.

[27] B. Gerull, M. Gramlich, J. Atherton et al., "Mutations of TTN, encoding the giant muscle filament titin, cause familial dilated cardiomyopathy," Nature Genetics, vol. 30, no. 2, pp. 201-204, 2002.

[28] T. M. Olson, S. Illenberger, N. Y. Kishimoto, S. Huttelmaier, M. T. Keating, and B. M. Jockusch, "Metavinculin mutations alter actin interaction in dilated cardiomyopathy," Circulation, vol. 105, no. 4, pp. 431-437, 2002.

[29] R. Knöll, M. Hoshijima, H. M. Hoffman et al., "The cardiac mechanical stretch sensor machinery involves a $\mathrm{Z}$ disc complex that is defective in a subset of human dilated cardiomyopathy," Cell, vol. 111, no. 7, pp. 943-955, 2002.

[30] B. Mohapatra, S. Jimenez, J. H. Lin et al., "Mutations in the muscle LIM protein and $\alpha$-actinin-2 genes in dilated cardiomyopathy and endocardial fibroelastosis," Molecular Genetics and Metabolism, vol. 80, no. 1-2, pp. 207-215, 2003.

[31] E. Carniel et al., "Molecular screening of alpha-myosin heavy chainin patients with dilated and hypertrophic cardiomyopathy," Circulation, vol. 108, no. 17, pp. 263-264, 2003.

[32] M. Bienengraeber, T. M. Olson, V. A. Selivanov et al., "ABCC9 mutations identified in human dilated cardiomyopathy disrupt catalytic KATP channel gating," Nature Genetics, vol. 36, no. 4, pp. 382-387, 2004.

[33] D. Fatkin, C. Macrae, T. Sasaki et al., "Missense mutations in the rod domain of the lamin A/C gene as causes of dilated cardiomyopathy and conduction-system disease," New England Journal of Medicine, vol. 341, no. 23, pp. 17151724, 1999.

[34] J. P. Schmitt, M. Kamisago, M. Asahi et al., "Dilated cardiomyopathy and heart failure caused by a mutation in phospholamban," Science, vol. 299, no. 5611, pp. 1410-1413, 2003.

[35] K. Haghighi, F. Kolokathis, L. Pater et al., "Human phospholamban null results in lethal dilated cardiomyopathy revealing a critical difference between mouse and human," Journal of Clinical Investigation, vol. 111, no. 6, pp. 869-876, 2003.

[36] M. Vatta, B. Mohapatra, S. Jimenez et al., "Mutations in cypher/ZASP in patients with dilated cardiomyopathy and left ventricular non-compaction," Journal of the American College of Cardiology, vol. 42, no. 11, pp. 2014-2027, 2003. 
[37] F. Muntoni, M. Cau, A. Ganau et al., "Brief report: deletion of the dystrophin muscle-promoter region associated with X-linked dilated cardiomyopathy," New England Journal of Medicine, vol. 329, no. 13, pp. 921-925, 1993.

[38] J. A. Towbin, J. F. Hejtmancik, P. Brink et al., "X-linked dilated cardiomyopathy: molecular genetic evidence of linkage to the Duchenne muscular dystrophy (dystrophin) gene at the Xp21 locus," Circulation, vol. 87, no. 6, pp. 1854-1865, 1993.

[39] S. Bione, P. D’Adamo, E. Maestrini, A. K. Gedeon, P. A. Bolhuis, and D. Toniolo, "A novel X-linked gene, G4.5. is responsible for Barth syndrome," Nature Genetics, vol. 12, no. 4, pp. 385-389, 1996.

[40] P. D’Adamo, L. Fassone, A. Gedeon et al., "The X-linked gene G4.5 is responsible for different infantile dilated cardiomyopathies," American Journal of Human Genetics, vol. 61, no. 4, pp. 862-867, 1997.

[41] R. T. Murphy, J. Mogensen, A. Shaw, T. Kubo, S. Hughes, and W. J. McKenna, "Novel mutation in cardiac troponin I in recessive idiopathic dilated cardiomyopathy," Lancet, vol. 363, no. 9406, pp. 371-372, 2004.

[42] A. Rampazzo, A. Nava, G. A. Danieli et al., "The gene for arrhythmogenic right ventricular cardiomyopathy maps to chromosome 14q23-q24," Human Molecular Genetics, vol. 3, no. 6, pp. 959-962, 1994.

[43] A. Rampazzo, G. Beffagna, A. Nava et al., "Arrhythmogenic right ventricular cardiomyopathy type 1 (ARVD1): confirmation of locus assignment and mutation screening of four candidate genes," European Journal of Human Genetics, vol. 11, no. 1, pp. 69-76, 2003.

[44] A. Rampazzo, A. Nava, P. Erne et al., "A new locus for arrhythmogenic right ventricular cardiomyopathy (ARVD2) maps to chromosome 1q42-q43," Human Molecular Genetics, vol. 4, no. 11, pp. 2151-2154, 1995.

[45] S. O. Marx, S. Reiken, Y. Hisamatsu et al., "PKA phosphorylation dissociates FKBP12.6 from the calcium release channel (ryanodine receptor): defective regulation in failing hearts," Cell, vol. 101, no. 4, pp. 365-376, 2000.

[46] G. M. Severini, M. Krajinovic, B. Pinamonti et al., "A new locus for arrhythmogenic right ventricular dysplasia on the long arm of chromosome 14," Genomics, vol. 31, no. 2, pp. 193-200, 1996.

[47] A. Rampazzo, A. Nava, M. Miorin et al., "ARVD4, a new locus for arrhythmogenic right ventricular cardiomyopathy, maps to chromosome 2 long arm," Genomics, vol. 45, no. 2, pp. 259-263, 1997.

[48] F. Ahmad, D. Li, A. Karibe et al., "Localization of a gene responsible for arrhythmogenic right ventricular dysplasia to chromosome 3p23," Circulation, vol. 98, no. 25, pp. 27912795, 1998.

[49] Y. Asano, S. Takashima, M. Asakura et al., "Lamr1 functional retroposon causes right ventricular dysplasia in mice," Nature Genetics, vol. 36, no. 2, pp. 123-130, 2004.

[50] D. Li, F. Ahmad, M. J. Gardner et al., "The locus of a novel gene responsible for arrhythmogenic right- ventricular dysplasia characterized by early onset and high penetrance maps to chromosome 10p12-p14," American Journal of Human Genetics, vol. 66, no. 1, pp. 148-156, 2000.

[51] D. Li, O. Gonzalez, L. L. Bachinski, and R. Roberts, "Human protein tyrosine phosphatase-like gene: expression profile, genomic structure, and mutation analysis in families with ARVD," Gene, vol. 256, no. 1-2, pp. 237-243, 2000.
[52] A. Melberg, A. Oldfors, C. Blomström-Lundqvist et al., "Autosomal dominant myofibrillar myopathy with arrhythmogenic right ventricular cardiomyopathy linked to chromosome 10q," Annals of Neurology, vol. 46, no. 5, pp. 684-692, 1999.

[53] A. Ferreiro, C. Ceuterick-De Groote, J. J. Marks et al., "Desmin-related myopathy with mallory body-like inclusions is caused by mutations of the selenoprotein N gene," Annals of Neurology, vol. 55, no. 5, pp. 676-686, 2004.

[54] G. M. Olavesen, E. Bentley, R. F. Mason, R. J. Stephens, and J. Ragoussis, "Fine mapping of 39 ESTs on human chromosome 6p23-p25," Genomics, vol. 46, no. 2, pp. 303-306, 1997.

[55] B. Gerull, A. Heuser, T. Wichter et al., "Mutations in the desmosomal protein plakophilin-2 are common in arrhythmogenic right ventricular cardiomyopathy," Nature Genetics, vol. 36, no. 11, pp. 1162-1164, 2004.

[56] S. Bonné, J. Van Hengel, and F. Van Roy, "Chromosomal mapping of human armadillo genes belonging to the p120(ctn)/plakophilin subfamily," Genomics, vol. 51, no. 3, pp. 452-454, 1998.

[57] P. Syrris, D. Ward, A. Evans et al., "Arrhythmogenic right ventricular dysplasia/cardiomyopathy associated with mutations in the desmosomal gene desmocollin-2," American Journal of Human Genetics, vol. 79, no. 5, pp. 978-984, 2006.

[58] J. Arnemann, N. K. Spurr, A. I. Magee, and R. S. Buxton, "The human gene (DSG2) coding for HDGC, a second member of the desmoglein subfamily of the desmosomal cadherins, is, like DSG1 coding for desmoglein DGI, assigned to chromosome 18," Genomics, vol. 13, no. 2, pp. 484-486, 1992.

[59] M. D. Greenwood, M. D. Marsden, C. M. E. Cowley, V. K. Sahota, and R. S. Buxton, "Exon-intron organization of the human type 2 desmocollin gene (DSC2): desmocollin gene structure is closer to "classical" cadherins than to desmogleins," Genomics, vol. 44, no. 3, pp. 330-335, 1997.

[60] R. S. Buxton, G. N. Wheeler, S. C. Pidsley et al., "Mouse desmocollin (Dsc3) and desmoglein (Dsg1) genes are closely linked in the proximal region of chromosome 18," Genomics, vol. 21, no. 3, pp. 510-516, 1994.

[61] P. Richardson, R. W. McKenna, M. Bristow et al., "Report of the 1995 World Health Organization/International Society and Federation of Cardiology Task Force on the definition and classification of cardiomyopathies," Circulation, vol. 93, no. 5, pp. 841-842, 1996.

[62] P. Elliott, "The 2006 American Heart Association classification of cardiomyopathies is not the gold standard," Circulation, vol. 1, no. 1, pp. 77-80, 2008.

[63] B. J. Maron, "Is the 2006 American Heart Association classification of cardiomyopathies the gold standard? The 2006 American Heart Association Classification of Cardiomyopathies Is the Gold Standard," Circulation, vol. 1, no. 1, pp. 72-76, 2008.

[64] G. Thiene, D. Corrado, and C. Basso, "Cardiomyopathies: is it time for a molecular classification?" European Heart Journal, vol. 25, no. 20, pp. 1772-1775, 2004.

[65] B. Maisch, M. Noutsias, V. Ruppert, A. Richter, and S. Pankuweit, "Cardiomyopathies: classification, diagnosis, and treatment," Heart Failure Clinics, vol. 8, no. 1, pp. 53-78, 2012.

[66] P. Charron and M. Komajda, "Molecular genetics in hypertrophic cardiomyopathy: towards individualized management of the disease," Expert Review of Molecular Diagnostics, vol. 6, no. 1, pp. 65-78, 2006. 
[67] P. Elliott and W. J. McKenna, "Hypertrophic cardiomyopathy," Lancet, vol. 363, no. 9424, pp. 1881-1891, 2004.

[68] B. J. Maron, "Hypertrophic cardiomyopathy," Circulation, vol. 106, no. 19, pp. 2419-2421, 2002.

[69] P. Richard, V. Fressart, P. Charron, and B. Hainque, "Genetics of inherited cardiomyopathies," Pathologie Biologie, vol. 58, no. 5, pp. 343-352, 2010.

[70] P. Richard, E. Villard, P. Charron, and R. Isnard, "The genetic bases of cardiomyopathies," Journal of the American College of Cardiology, vol. 48, no. 9, pp. A79-A89, 2006.

[71] R. E. Hershberger, J. Lindenfeld, L. Mestroni, C. E. Seidman, M. R. G. Taylor, and J. A. Towbin, "Genetic evaluation of cardiomyopathy - a heart failure society of America practice guideline," Journal of Cardiac Failure, vol. 15, no. 2, pp. 8397, 2009.

[72] Q. Xu, S. Dewey, S. Nguyen, and A. V. Gomes, "Malignant and benign mutations in familial cardiomyopathies: insights into mutations linked to complex cardiovascular phenotypes," Journal of Molecular and Cellular Cardiology, vol. 48, no. 5, pp. 899-909, 2010.

[73] J. R. Gimeno, L. Monserrat, I. Pérez-Sánchez et al., "Hypertrophic cardiomyopathy. A study of the troponin-T gene in 127 Spanish families," Revista Espanola de Cardiologia, vol. 62, no. 12, pp. 1473-1477, 2009.

[74] B. J. Maron, W. J. McKenna, G. K. Danielson et al., "American College of Cardiology/European Society of Cardiology Clinical Expert Consensus Document on Hypertrophic Cardiomyopathy: a report of the American College of cardiology foundation task force on clinical expert consensus documents and the European society of cardiology committee for practice guidelines," European Heart Journal, vol. 24, no. 21, pp. 1965-1991, 2003.

[75] B. J. Maron, "Sudden death in hypertrophic cardiomyopathy," Journal of Cardiovascular Translational Research, vol. 2, no. 4, pp. 368-380, 2009.

[76] C. M. Oakley, "Report of the WHO/ISFC task force on the definition and classification of cardiomyopathies," British Heart Journal, vol. 44, no. 6, pp. 672-673, 1980.

[77] J. R. Benotti, W. Grossman, and P. F. Cohn, "Clinical profile of restrictive cardiomyopathy," Circulation, vol. 61, no. 6, pp. 1206-1212, 1980.

[78] N. Rajagopalan, M. J. Garcia, L. Rodriguez et al., "Comparison of new Doppler echocardiographic methods to differentiate constrictive pericardial heart disease and restrictive cardiomyopathy," American Journal of Cardiology, vol. 87, no. 1, pp. 86-94, 2001.

[79] S. S. Kushwaha, J. T. Fallon, and V. Fuster, "Medical progress-restrictive cardiomyopathy," New England Journal of Medicine, vol. 336, no. 4, pp. 267-276, 1997.

[80] A. P. Fitzpatrick, L. M. Shapiro, A. F. Rickards, and P. A. Poole-Wilson, "Familial restrictive cardiomyopathy with atrioventricular block and skeletal myopathy," British Heart Journal, vol. 63, no. 2, pp. 114-118, 1990.

[81] N. M. Ammash, J. B. Seward, K. R. Bailey, W. D. Edwards, and A. J. Tajik, "Clinical profile and outcome of idiopathic restrictive cardiomyopathy," Circulation, vol. 101, no. 21, pp. 2490-2496, 2000.

[82] M. R. G. Taylor, E. Carniel, and L. Mestroni, "Cardiomyopathy, familial dilated," Orphanet Journal of Rare Diseases, vol. 1 , no. 1 , article 27, 2006.

[83] J. A. Towbin, A. M. Lowe, S. D. Colan et al., "Incidence, causes, and outcomes of dilated cardiomyopathy in children," Journal of the American Medical Association, vol. 296, no. 15, pp. 1867-1876, 2006.
[84] J. A. Towbin and N. E. Bowles, "The failing heart," Nature, vol. 415, no. 6868, pp. 227-233, 2002.

[85] J. U. Hibbard, M. Lindheimer, and R. M. Lang, "A modified definition for peripartum cardiomyopathy and prognosis based on echocardiography," Obstetrics and Gynecology, vol. 94, no. 2, pp. 311-316, 1999.

[86] L. Johnson-Coyle, L. Jensen, and A. Sobey, "Peripartum cardiomyopathy: review and practice guidelines," American Journal of Critical Care, vol. 21, no. 2, pp. 89-99, 2012.

[87] U. Elkayam, M. W. Akhter, H. Singh et al., "Pregnancyassociated cardiomyopathy: clinical characteristics and a comparison between early and late presentation," Circulation, vol. 111, no. 16, pp. 2050-2055, 2005.

[88] K. Sliwa, J. Fett, and U. Elkayam, "Peripartum cardiomyopathy," Lancet, vol. 368, no. 9536, pp. 687-693, 2006.

[89] O. Forster, D. Hilfiker-Kleiner, A. A. Ansari et al., "Reversal of IFN- $\gamma$, oxLDL and prolactin serum levels correlate with clinical improvement in patients with peripartum cardiomyopathy," European Journal of Heart Failure, vol. 10, no. 9, pp. 861-868, 2008.

[90] J. Marmursztejn, O. Vignaux, F. Goffinet, L. Cabanes, and D. Duboc, "Delayed-enhanced cardiac magnetic resonance imaging features in peripartum cardiomyopathy," International Journal of Cardiology, vol. 137, no. 3, pp. e63-e64, 2009.

[91] A. E. Baruteau, G. Leurent, R. P. Martins et al., "Peripartum cardiomyopathy in the era of cardiac magnetic resonance imaging: first results and perspectives," International Journal of Cardiology, vol. 144, no. 1, pp. 143-145, 2010.

[92] A. A. Ansari, J. D. Fett, R. E. Carraway, A. E. Mayne, N. Onlamoon, and J. B. Sundstrom, "Autoimmune mechanisms as the basis for human peripartum cardiomyopathy," Clinical Reviews in Allergy and Immunology, vol. 23, no. 3, pp. 301324, 2002.

[93] K. Sliwa, O. Förster, E. Libhaber et al., "Peripartum cardiomyopathy: inflammatory markers as predictors of outcome in 100 prospectively studied patients," European Heart Journal, vol. 27, no. 4, pp. 441-446, 2006.

[94] G. Torre-Amione, S. Kapadia, C. Benedict, H. Oral, J. B. Young, and D. L. Mann, "Proinflammatory cytokine levels in patients with depressed left ventricular ejection fraction: a report from the studies of left ventricular dysfunction (SOLVD)," Journal of the American College of Cardiology, vol. 27, no. 5, pp. 1201-1206, 1996.

[95] B. Bozkurt, F. S. Villaneuva, R. Holubkov et al., "Intravenous immune globulin in the therapy of peripartum cardiomyopathy," Journal of the American College of Cardiology, vol. 34, no. 1, pp. 177-180, 1999.

[96] K. Sliwa, D. Skudicky, G. Candy, A. Bergemann, M. Hopley, and P. Sareli, "The addition of pentoxifylline to conventional therapy improves outcome in patients with peripartum cardiomyopathy," European Journal of Heart Failure, vol. 4, no. 3, pp. 305-309, 2002.

[97] M. N. Rizeq, P. R. Rickenbacher, M. B. Fowler, and M. E. Billingham, "Incidence of myocarditis in peripartum cardiomyopathy," American Journal of Cardiology, vol. 74, no. 5, pp. 474-477, 1994.

[98] D. Hilfiker-Kleiner, K. Kaminski, E. Podewski et al., "A cathepsin $\mathrm{D}$-cleaved $16 \mathrm{kDa}$ form of prolactin mediates postpartum cardiomyopathy," Cell, vol. 128, no. 3, pp. 589600, 2007.

[99] U. Elkayam and S. Goland, "Bromocriptine for the treatment of peripartum cardiomyopathy," Circulation, vol. 121, no. 13, pp. 1463-1464, 2010. 
[100] G. Thiene, D. Corrado, and C. Basso, "Arrhythmogenic right ventricular cardiomyopathy/dysplasia," Orphanet Journal of Rare Diseases, vol. 2, no. 1, article 45, 2007.

[101] W. J. McKenna et al., "Diagnosis of arrhythmogenic right ventricular dysplasia/cardiomyopathy. Task Force of the Working Group Myocardial and Pericardial Disease of the European Society of Cardiology and of the Scientific Council on Cardiomyopathies of the International Society and Federation of Cardiology," British Heart Journal, vol. 71, no. 3, pp. 215-218, 1994.

[102] D. Corrado, L. Leoni, M. S. Link et al., "Implantable cardioverter-defibrillator therapy for prevention of sudden death in patients with arrhythmogenic right ventricular cardiomyopathy/dysplasia," Circulation, vol. 108, no. 25, pp. 3084-3091, 2003.

[103] A. Nava, G. Thiene, B. Canciani et al., "Familial occurrence of right ventricular dysplasia: a study involving nine families," Journal of the American College of Cardiology, vol. 12, no. 5, pp. 1222-1228, 1988.

[104] K. Pilichou, A. Nava, C. Basso et al., "Mutations in desmoglein-2 gene are associated with arrhythmogenic right ventricular cardiomyopathy," Circulation, vol. 113, no. 9, pp. 1171-1179, 2006.

[105] A. Rampazzo, "Regulatory mutations in transforming growth factor-beta 3 gene cause arrhythmogenic right ventricular cardiomyopathy type 1," Journal of the American College of Cardiology, vol. 45, no. 3, pp. 10A-11A, 2005.

[106] A. Rampazzo, A. Nava, S. Malacrida et al., "Mutation in human desmoplakin domain binding to plakoglobin causes a dominant form of arrhythmogenic right ventricular cardiomyopathy," American Journal of Human Genetics, vol. 71, no. 5, pp. 1200-1206, 2002.

[107] N. Tiso, D. A. Stephan, A. Nava et al., "Identification of mutations in the cardiac ryanodine receptor gene in families affected with arrhythmogenic right ventricular cardiomyopathy type 2 (ARVD2)," Human Molecular Genetics, vol. 10, no. 3, pp. 189-194, 2001.

[108] M. W. Chung, T. Tsoutsman, and C. Semsarian, "Hypertrophic cardiomyopathy: from gene defect to clinical disease," Cell Research, vol. 13, no. 1, pp. 9-20, 2003.

[109] R. E. Hershberger, A. Morales, and J. D. Siegfried, "Clinical and genetic issues in dilated cardiomyopathy: a review for genetics professionals," Genetics in Medicine, vol. 12, no. 11, pp. 655-667, 2010.

[110] R. J. Hajjar, F. Del Monte, T. Matsui, and A. Rosenzweig, "Prospects for gene therapy for heart failure," Circulation Research, vol. 86, no. 6, pp. 616-621, 2000.

[111] F. I. Marcus and W. Zareba, "The electrocardiogram in right ventricular cardiomyopathy/dysplasia. How can the electrocardiogram assist in understanding the pathologic and functional changes of the heart in this disease?" Journal of Electrocardiology, vol. 42, no. 2, pp. 136.e1-136.e5, 2009.

[112] E. D. Wigle, H. Rakowski, B. P. Kimball, and W. G. Williams, "Hypertrophic cardiomyopathy: clinical spectrum and treatment," Circulation, vol. 92, no. 7, pp. 1680-1692, 1995.

[113] E. Abergel, G. Chatellier, A. A. Hagege et al., "Serial left ventricular adaptations in world-class professional cyclists: implications for disease screening and follow-up," Journal of the American College of Cardiology, vol. 44, no. 1, pp. 144149, 2004.

[114] R. A. Nishimura and D. R. Holmes, "Hypertrophic obstructive cardiomyopathy," New England Journal of Medicine, vol. 350, no. 13, pp. 1320-1327, 2004.
[115] S. Sen-Chowdhry, P. Syrris, and W. J. McKenna, "Genetics of right ventricular cardiomyopathy," Journal of Cardiovascular Electrophysiology, vol. 16, no. 8, pp. 927-935, 2005.

[116] G. Quarta, A. Muir, A. Pantazis et al., "Familial evaluation in arrhythmogenic right ventricular cardiomyopathy: impact of genetics and revised task force criteria," Circulation, vol. 123, no. 23, pp. 2701-2709, 2011.

[117] A. Karibe, L. S. Tobacman, J. Strand et al., "Hypertrophic cardiomyopathy caused by a novel $\alpha$-tropomyosin mutation (V95A) is associated with mild cardiac phenotype, abnormal calcium binding to troponin, abnormal myosin cycling, and poor prognosis," Circulation, vol. 103, no. 1, pp. 65-71, 2001.

[118] H. Niimura, L. L. Bachinski, S. Sangwatanaroj et al., "Mutations in the gene for cardiac myosin-binding protein $\mathrm{C}$ and late- onset familial hypertrophic cardiomyopathy," New England Journal of Medicine, vol. 338, no. 18, pp. 1248-1257, 1998.

[119] A. P. Landstrom and M. J. Ackerman, "Mutation type is not clinically useful in predicting prognosis in hypertrophic cardiomyopathy," Circulation, vol. 122, no. 23, pp. 2441$2449,2010$. 

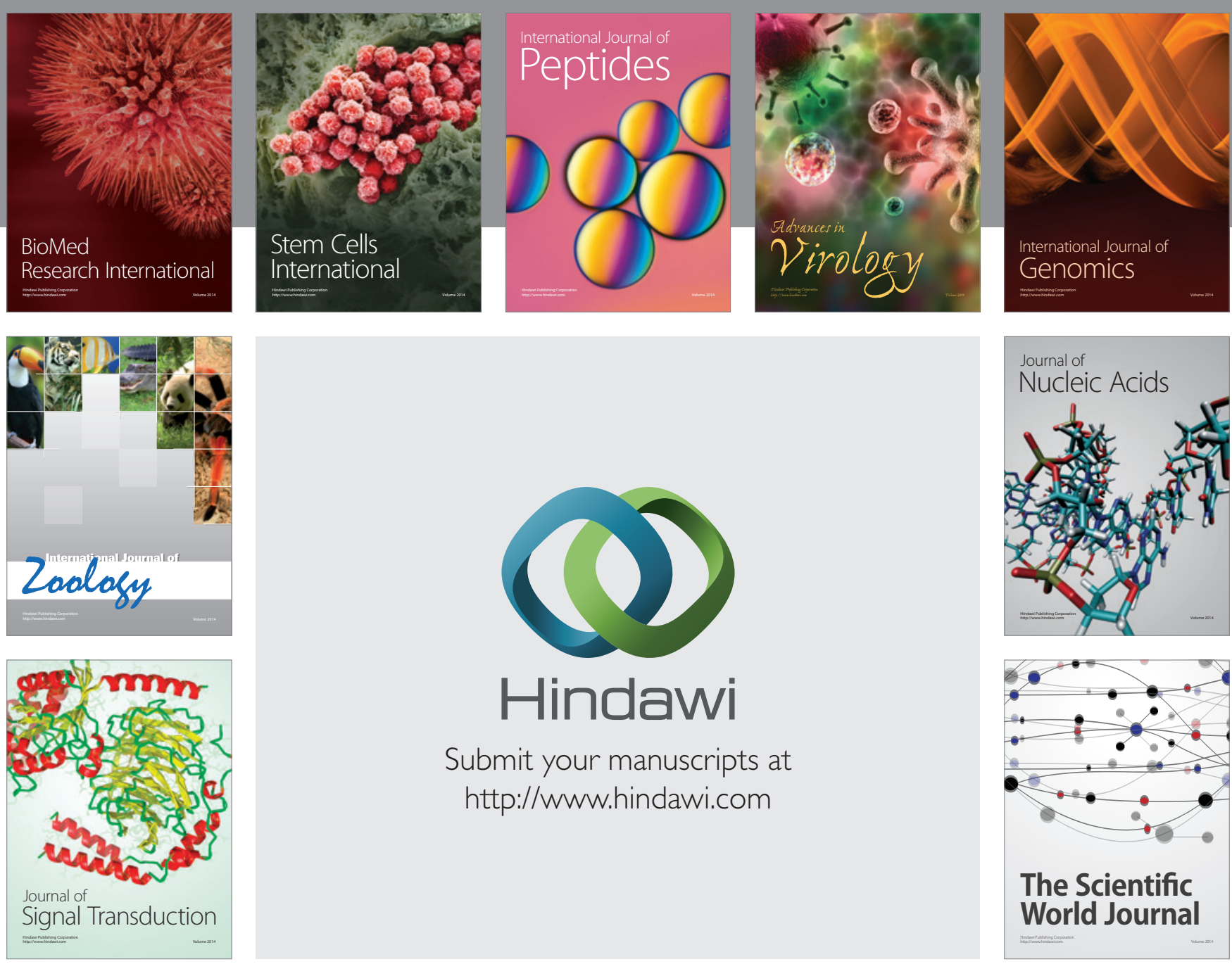

Submit your manuscripts at

http://www.hindawi.com
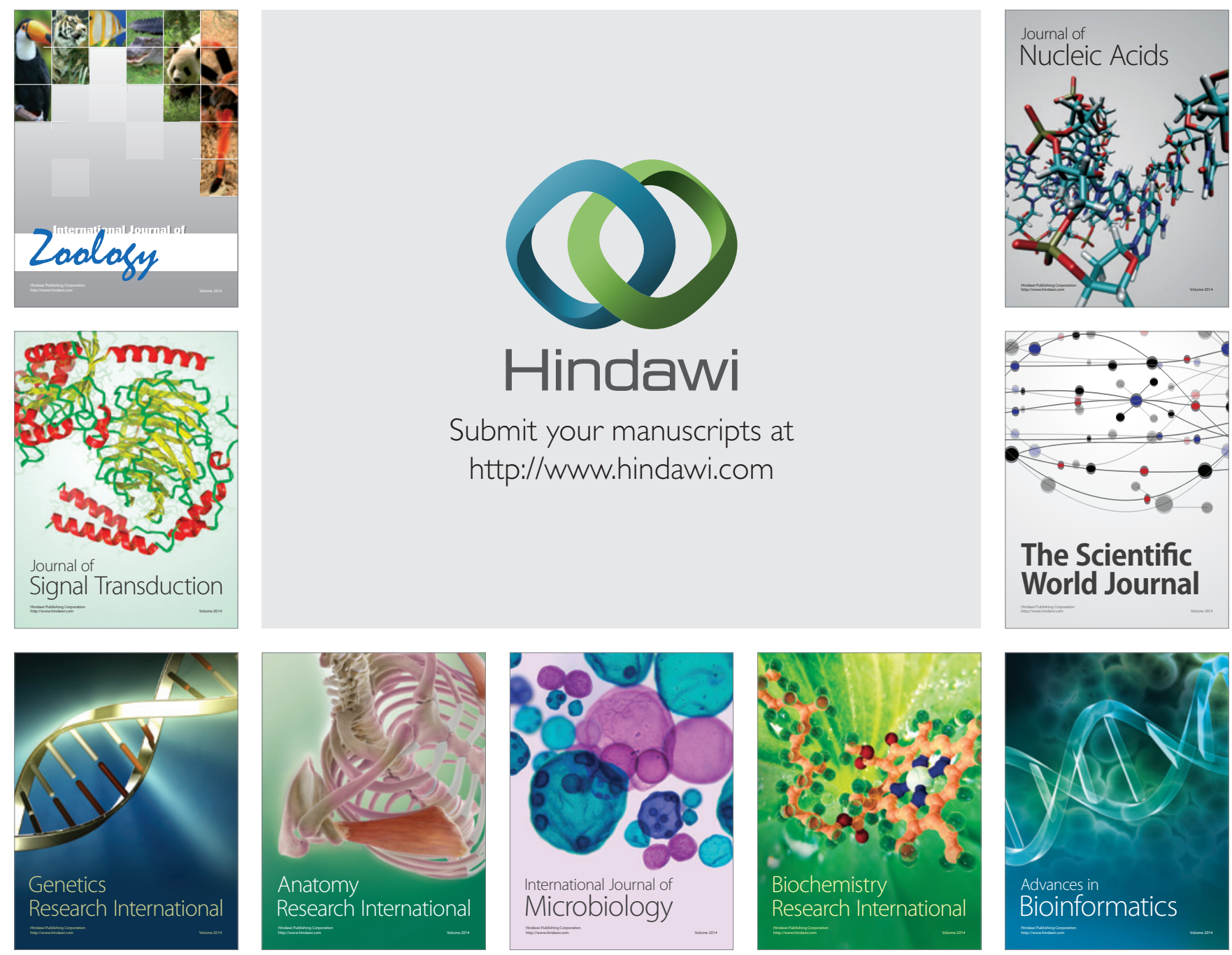

The Scientific World Journal
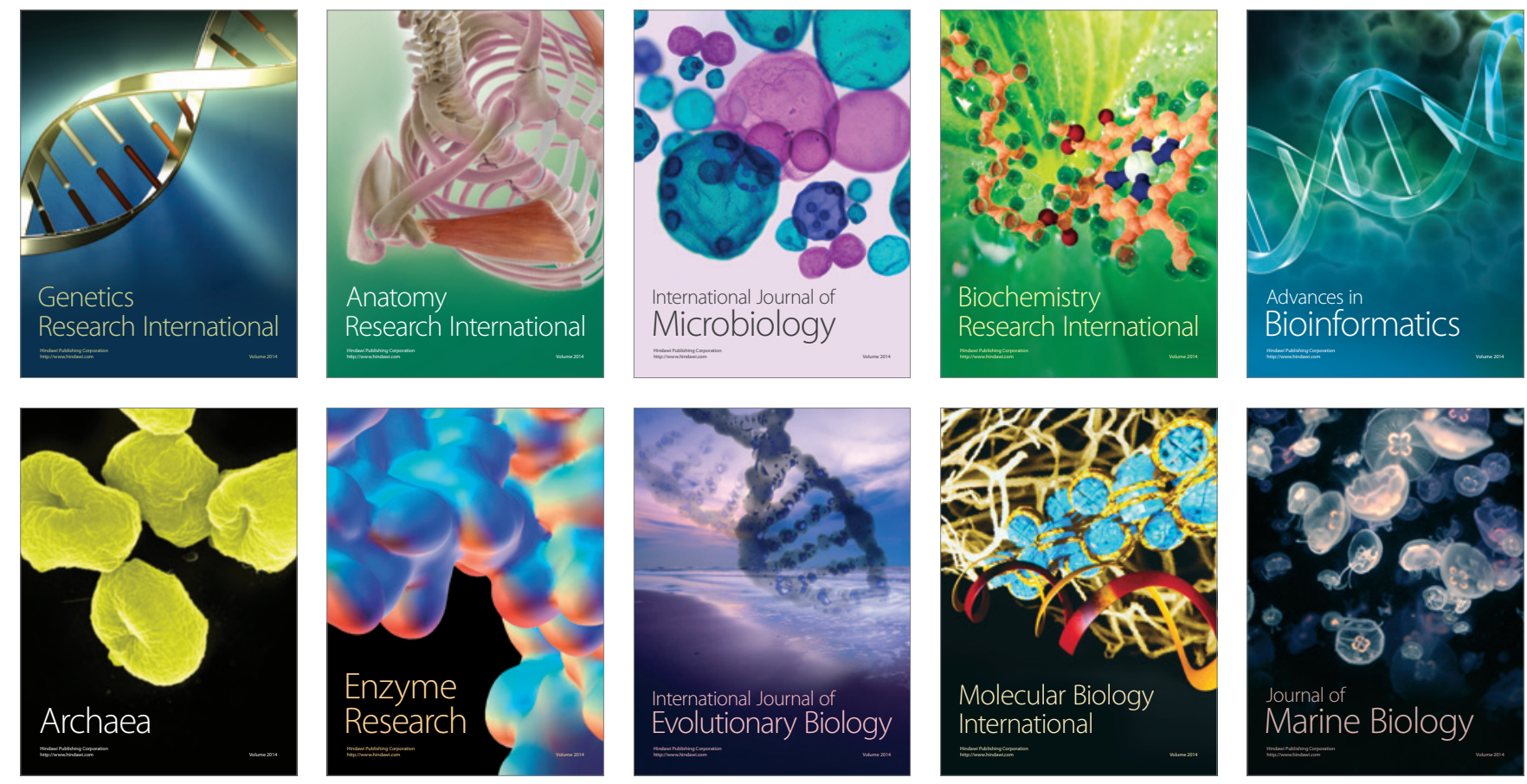